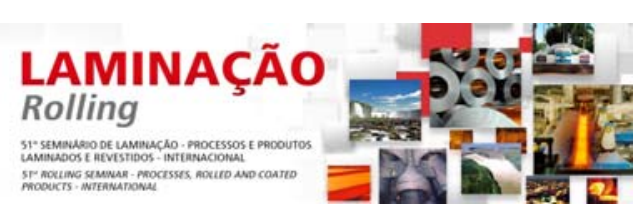

\title{
AN EFFECTIVE INTER STAND COOLING IN HOT STRIP MILL*
}

Jan Knobloch ${ }^{1}$ Daniel Hajduk ${ }^{2}$

\begin{abstract}
Inter Stand Cooling (ISC) can increase productivity of a HSM and improve final mechanical properties of the strip. Constant Target Exit Temperature can be ensured for the whole strip length eliminating skid marks and other temperature oscillations of the transfer bar. The paper deals with advanced control module of ISC. Essential mathematical models of the control system is introduced and basic functionality is explained. Temperature model is based on FEM. Mechanical and thermal properties of the strip are calculated from chemical composition using neural network. Further on an experimental possibilities for investigation and design of ISC cooling headers will be shown. In conclusion practical experience with ISC on various HSM will be discussed.
\end{abstract}

Keywords: Inter stand cooling; Cooling headers; Final temperature control; Hot strip mill.

1 Ing., CEO, Process Automation, PT Solutions Worldwide spol. s r.o., Prague, Czech Republic.

2 Ing., Ph. D., Executive head, ITA Ltd., Ostrava, Czech Republic.

* Technical contribution to the $51^{\text {st }}$ Rolling Seminar - Processes, Rolled and Coated Products, October $28^{\text {th }}$ to $31^{\text {st }}$, 2014, Foz do Iguaçu, PR, Brazil. 


\section{INTRODUCTION}

The Inter Stand Cooling at wide strip hot mills partakes fundamentally in reaching and maintaining the required exit rolling temperature (ERT). Thus it enables to reach better and more homogeneous mechanical properties of a strip, particularly in micro alloyed steels. ERT can be maintained constant on the whole strip length, even when transfer bar temperature oscillates due to skid marks in slab or other reasons. Very important is the possibility to increase the mill production so that it enables to roll at higher speed or speed up. For the correct function of the Inter Stand Cooling it is necessary to fulfill two basic requirements - to keep at disposition an optimal hardware (cooling headers with sufficient cooling power including the possibility of fast and fluent regulation of flow rate) and the advanced control software, both for cooling setup, feed forward and feedback control.

\section{CONTROL SYSTEM of ISC}

Presented control system of ISC has been designed to work either within existing Level2 of the mill or to work rather independently of it. It consists of three basic parts - Setup (working within existing Level2 or on separate computer), Piece to piece adaptation and Long term adaptation. Basis scheme of the system is in Figure 1.

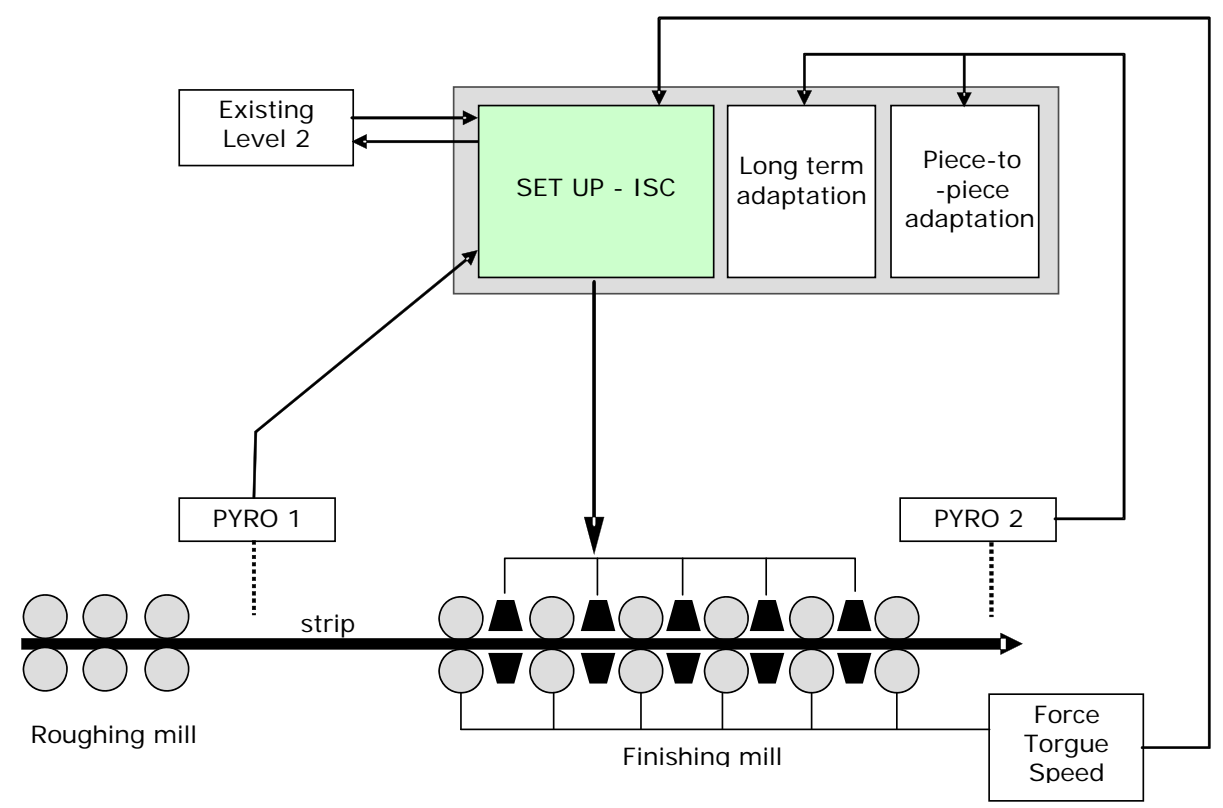

Figure 1. Basic scheme of the control system

The main task of the Setup is to calculate the number and power of cooling headers to reach the target temperature in the whole strip length. The measured strip temperature is mostly available only at limited number of spots, at outlet from the roughing mill, before the finishing mill and at the finishing mill outlet. Nevertheless, the temperature measuring before the finishing mill entry is usually very unreliable because it is influenced by a thick scale layer, emissivity of which strongly depend also on the steel chemical composition. As the transfer bar temperature oscillates, the number and cooling power of the headers (on terms of flow rates) must be calculated in several spots lengthwise. The points (coordinates) are situated in the local extremes of the temperature curve in the transfer bar. Special filter is used to

\footnotetext{
* Technical contribution to the $51^{\text {st }}$ Rolling Seminar - Processes, Rolled and Coated Products, October $28^{\text {th }}$ to $31^{\text {st }}$, 2014, Foz do Iguaçu, PR, Brazil.
} 


\section{SOFTWARE MODULES OF ISC}

\subsection{Temperature Model}

The temperature model has to describe the temperature field in the rolled strip for defined boundary conditions. Detailed multidimensional models can be used only in a limited way due to their demands for the processor's time. A compromise solution is 1-D physical model on the base of Finite Element Method which enables to calculate the temperature profile through the strip thickness in the given coordinate (point). The model neglects the heat conduction both across the width and along the length of the strip (Figure 4). However, understanding of the temperature along the length is very important and therefore it is necessary to calculate the temperature field in several points.

Boundary conditions cover

- Air cooling of a strip (heat radiation and convection),

- Water cooling with the help of an inter stand headers, roll cooling, descaler,

- Cooling in the rolling gap,

- Heat generation due to deformation in roll gap.

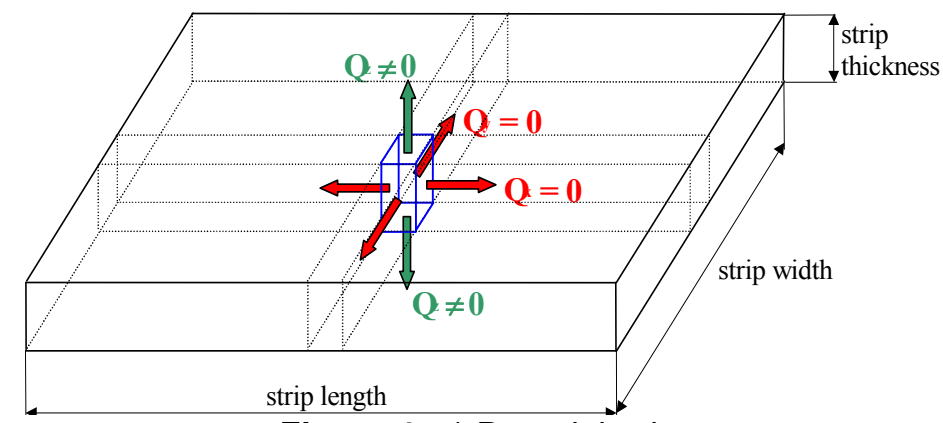

Figure 4 - 1-D model scheme

\subsection{Model for the Headers Setup (inverse function)}

The task of the model is a fast calculation of the cooling power and number of suitable headers so that the required exit rolling temperature is reached (for one examined point on the strip). For the calculation, the optimization method Merortha predictor corrector is applied. The algorithm scheme for one point with mutual relationship of both models is at Figure 3 .

Used constraints for the optimization calculation:

- Specific power of each of the headers must vary in between 0 (off) up to 1 (max. power)

- The header's power must be higher than or equal the next header (along the rolling course)

- The headers' power should be distributed so that strip is being cooled most at the largest thicknesses (for some steel grades this criterion will not be applied)

- To give priority to condition off or set on the full power.

* Technical contribution to the $51^{\text {st }}$ Rolling Seminar - Processes, Rolled and Coated Products, October $28^{\text {th }}$ to $31^{\text {st }}$, 2014, Foz do Iguaçu, PR, Brazil. 

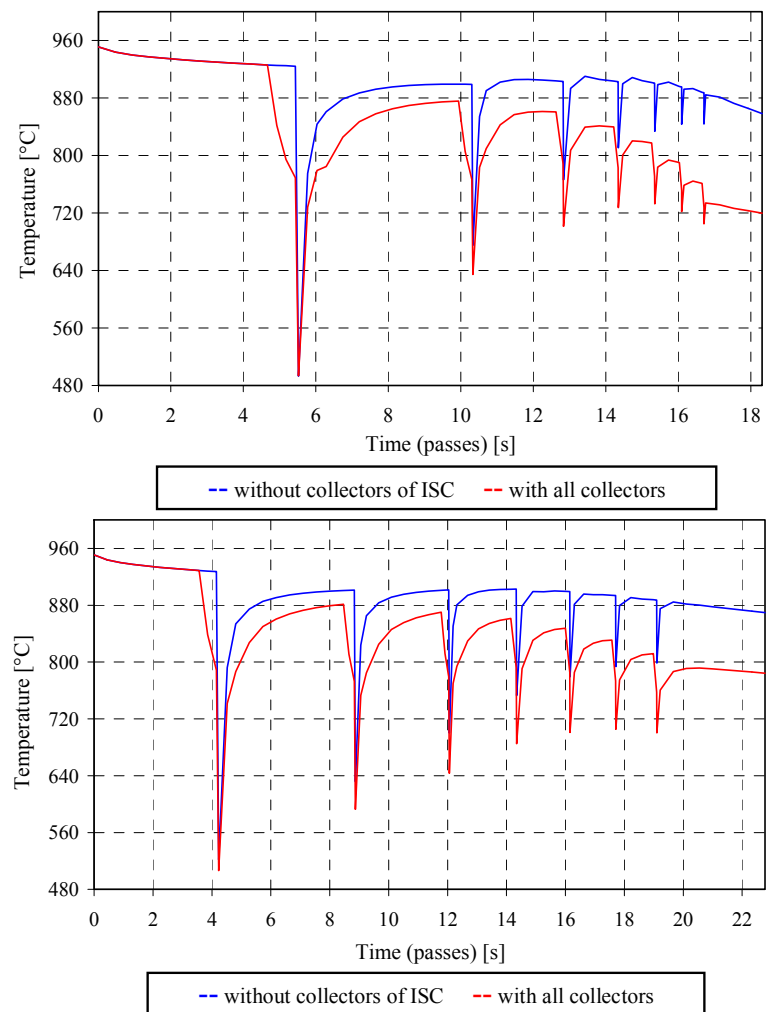

Figure 5. The efficiency of ISC in thin and thick strip

\subsection{Cooling Strategies}

There can be various cooling strategies applied, that can provide soft cooling, standard cooling or rapid skid mark elimination. Each of the strategies has advantages and disadvantages. Standard cooling is working with maximum cooling headers spraying with $100 \%$ flow rate. This is a very intensive cooling that removes skid marks rather late, in the last active interstand headers. But, the most intensive cooling and maximum temperature drop can be achieved.

Rapid skid mark elimination means intermittent cooling in early stands. Skid marks can be eliminated early - in first stand but cooling efficiency of the whole system is lower. That results in lower speed up and lower mill productivity in comparison with the standard cooling strategy. In some cases the soft cooling can be used. Soft cooling is characterized by limitations of cooling power (flow rate) on certain headers.

\footnotetext{
* Technical contribution to the $51^{\text {st }}$ Rolling Seminar - Processes, Rolled and Coated Products, October $28^{\text {th }}$ to $31^{\text {st }}$, 2014, Foz do Iguaçu, PR, Brazil.
} 


\subsection{Target Exit Rolling Temperature}

The target rolling temperature (ERT) can be kept lengthwise with a tolerance of \pm $10^{\circ} \mathrm{C}$ from the target temperature. In thin strips $(<4 \mathrm{~mm})$, the temperature deviations are less than $\pm 7^{\circ} \mathrm{C}$ on $95 \%$ of the strip length. In thick strips (>10 mm) the tolerance $\pm 12^{\circ} \mathrm{C}$ can be reached only if the temperature oscillation in transfer bar is less than $15^{\circ} \mathrm{C}$. During the system testing it was discovered deviation in target temperature at strip head and tail even the body temperature was controlled very precisely. The reason for this deviation was mainly due to the incorrect transfer bar temperature since temperature measurements at these parts are very unreliable.

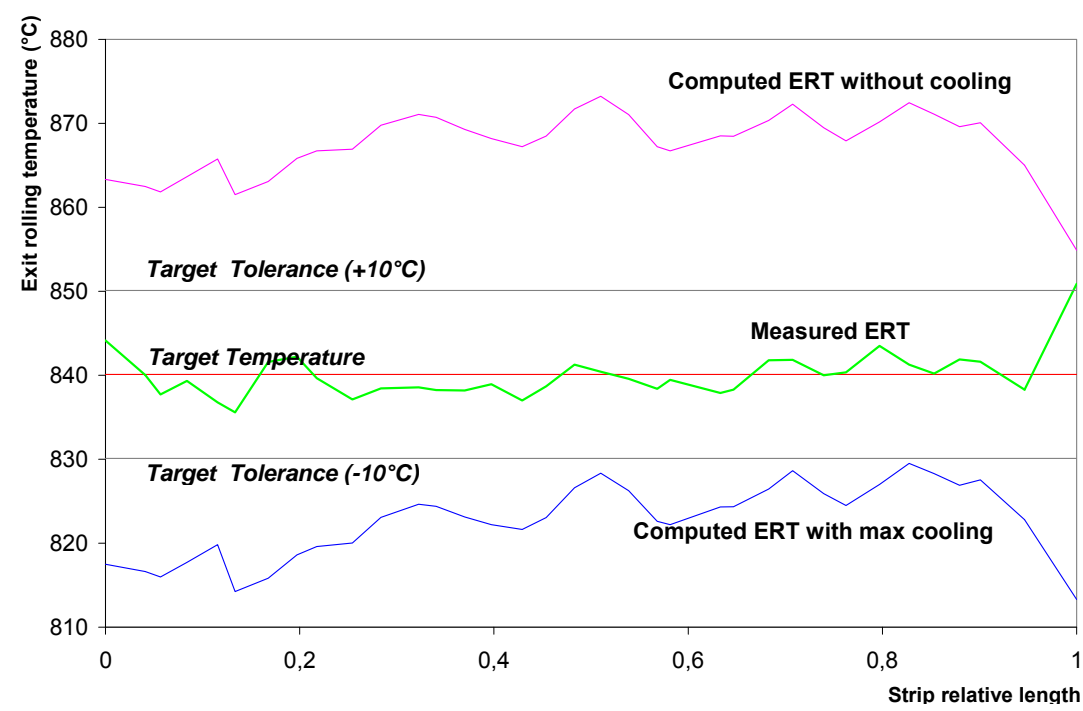

Figure. 10 Measured and Calculated ERT

\subsection{Elimination of Skid Marks}

ISC proved to be very effective tool to eliminate skid marks. If the slab is heated in older furnaces the temperature oscillation in transfer bar can be more than $30-40^{\circ} \mathrm{C}$. Those oscillations can be completely eliminated in thin strips $(<4 \mathrm{~mm})$. In thick strips (more than $12 \mathrm{~mm}$ ) temperature deviations up to $20{ }^{\circ} \mathrm{C}$ in transfer bar can be eliminated. Higher oscillations $\left(30-40^{\circ} \mathrm{C}\right)$ cannot be removed completely, but they can be considerably reduced.

\subsection{Enhancement of Speed/Speed up}

Required exit rolling temperature is one of the limiting parameters for speed and speedup of the strip. Providing that ISC has enough cooling power and flow rate on headers and can be effectively controlled the limits of speed and speedup can be raised. There are several metallurgical and technological aspects prohibiting extensive cooling in special steels where this way of increasing productivity can be used only in limited manner. Nevertheless practical experience proved an increase of productivity due to ISC when compared with rolling without ISC or using ISC with constant cooling power (flow rate) lengthwise. An example below demonstrates the cooling matrices of thin strips rolled at $14 \mathrm{~m} / \mathrm{s}$ and $21 \mathrm{~m} / \mathrm{s}$. When rolling with low speed the cooling is nearly off. When rolling with higher speed up (threading velocity of both strips was the same), the ISC works with maximum power on the tail.

\footnotetext{
* Technical contribution to the $51^{\text {st }}$ Rolling Seminar - Processes, Rolled and Coated Products, October $28^{\text {th }}$ to $31^{\text {st }}$, 2014, Foz do Iguaçu, PR, Brazil.
} 

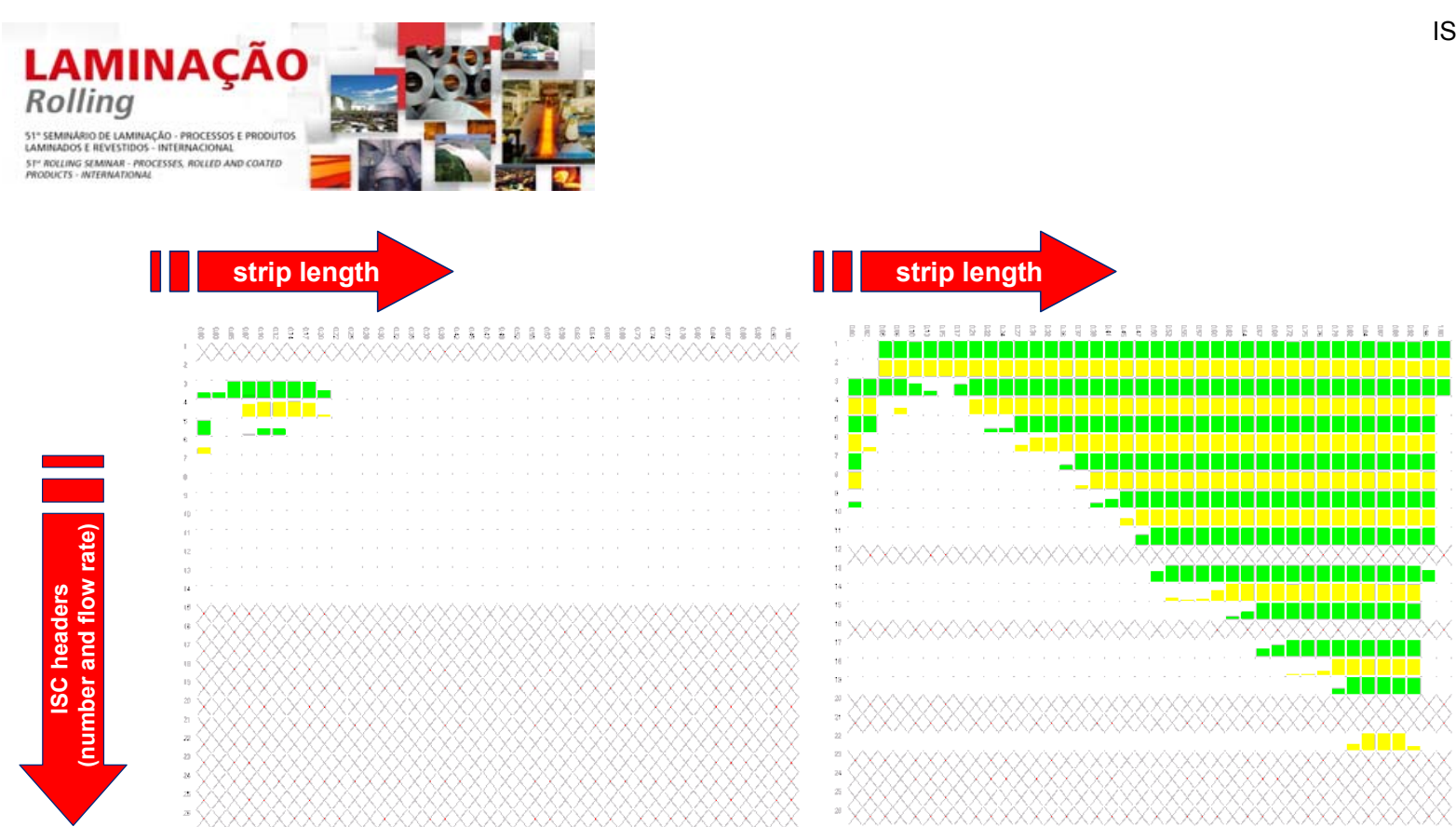

Figure 11. Cooling matrices for rolling velocity $14 \mathrm{~m} / \mathrm{s}$ (left) and $21 \mathrm{~m} / \mathrm{s}$ (right)

\section{CONCLUSION}

Complex approach to the Inter Stand Cooling problems was presented in this paper. Design of modern, more efficient cooling headers with help of laboratory measurements and evaluation of Heat transfer coefficient of headers have been shown. Software for control of exit rolling temperature has been shortly described together with the most important cooling strategies. Practical experience of revamped ISC has been discussed. New developed cooling strategies proved to increase productivity of the mill by higher rolling tempo. Exit rolling temperature can be kept in very narrow range. Temperature oscillations due to skid marks can be fully eliminated or considerably reduced. This helps to reduce number of temperature reclasses, enables better cooling of laminar section and achieving more homogenous mechanical properties of the strip as well as more stable rolling due to less oscillation of strip temperature and rolling speed.

\section{BIBLIOGRAPHY}

1 Horský J, Raudenský M, Zela L. Experimental Study of Heat Transfer with Reference to Numerical Simulations in Hot Rolling, The $7^{\text {th }}$ International Conference on Steel Rolling Proceedings, Makuhari, Chiba, Japan, The Iron and Steel Institute of Japan, pp. 216-220.

2 Raudenský M, Horský J, Pohanka M. Combined Inverse Heat Conduction Method for Highly Transient Processes," International Conference on Heat Transfer 2002, April 2224, 2002, Halkidiki, Greece, ISBN: 1- 85312-9062, ISSN: 1462-6063.

3 Hajduk D, Šimeček P. Models of Steel Behavior for Computer Simulation and Control of Rolling Processes, SARUC 2006 conference proceedings, Vanderbijlpark, South Africa, 2006. pp 75-78.

4 Hajduk D, Horský J, Raudenský M. Control of ISC on Hot Strip Mill," The $7^{\text {th }}$ International Conference Steel Strip 2006 Conference Proceedings, Přerov, Czech Republic, 2006, p. 95-102, ISBN 80-239-7750-4

5 D. Hajduk, P. Šimeček, M. Raudenský, "Interstand Cooling in Hot Strip Mill," $17^{\text {th }}$ Rolling Conference, Conference Proceedings. Instituto Argentino de Siderurgia. Rosario, Argentina. $10-13^{\text {rd }}$ November 2008.

\footnotetext{
* Technical contribution to the $51^{\text {st }}$ Rolling Seminar - Processes, Rolled and Coated Products, October $28^{\text {th }}$ to $31^{\text {st }}$, 2014, Foz do Iguaçu, PR, Brazil.
} 